\title{
Ortopedi ve Travmatolojide tıbbi malzeme yönetimi için yasal prosedürler ve kalite sorunu
}

\author{
Legal procedures and quality problems for implant management \\ in orthopedics and traumatology
}

\author{
Murat Altay, Mustafa Caner Okkaoğlu \\ Sağlık Bilimleri Üniversitesi, Keçiören Eğitim ve Araştırma Hastanesi, Ankara
}

\begin{abstract}
Ortopedi ve Travmatoloji alanındaki cerrahi yaklaşımlarda tıbbi malzemeler önemli yer tutmaktadır. Bir Ortopedi ve Travmatoloji uzmanı hastası için en uygun malzemeyi seçerken; yeni teknolojiyi takip etmeli, hastası için en uygun tıbbi malzemeyi tercih etmelidir. Ancak bu tercihi yaparken, ülkemizdeki yasal prosedürleri, sigorta kurumlarının kısıtlamalarını ve hasta ile ilgili faktörleri de göz önünde bulundurmak durumundadır. Bu çalışmada; özellikle kamu hastanesinde çalışan bir Ortopedi ve Travmatoloji uzmanının hastası için en uygun tıbbi malzemeyi kullanırken, Sağlık Uygulama Tebliğini (SUT) göz önüne alarak, dikkat etmesi gereken yasal prosedürlerin vurgulanması amaçlanmıştır. Ülkemizde malzeme kullanımını belirleyen en önemli faktörlerden biri Sosyal Güvenlik Kurumu'nun (SGK) geri ödeme kısıtlamaları ve fiyatlandırma politikalarıdır. illk olarak 2010 yılında yayımlanan ve daha sonra ihtiyaca göre güncellenen SUT; özellikle kamu hastanelerinde çalışan ortopedistlerin geri ödeme kapsamında kullanabilecekleri tıbbi malzemelerin sınırlarını belirler. SUT listelerindeki bazı ürünlerin kullanımı özel şartlara bağlanmaktadır. Bu nedenle, hekimin malzeme seçimi yaparken her zaman SUT'un güncel halini takip etmesi gerekmektedir. Artan firma giderlerine karşın (hammadde, kur, maliyet, istihdam, sigorta gibi) yeteri kadar artmayan fiyatlandırmalar ve kalite ayrımı yapmaksızın aynı SUT koduna tek fiyat verilmesi, özellikle dünya pazarında önemli yer işgal eden, pazar lideri, kaliteli ürün sunmaya çaIışan firmaların ülke pazarından çekilmesine yol açmaktadır. Bu da kullanılan malzemelerin kalitesinde düşmeye, yapılan ameliyatların başarısının azalmasına ve revizyon oranlarının günden güne artmasına yol açmaktadır. Bu konuda özellikle yerli üretimlerin desteklenmesi, kalitelerinin artırılması, araştırma-geliş̧tirme birimlerinin geliştirilmesi gerekmektedir. Tüm kullanılan malzemelerin denetim ve kalite kontrol sistemlerinden geçirilmesi önem arz etmektedir. Hekim bir tıbbi malzemeyi seçerken; ülkenin şartlarını, hastasının beklentilerini ve yaşam standartlarını göz önünde bulundurarak, yasal prosedürlere (SUT hükümlerine) dikkat ederek, maliyet-yarar oranı en uygun, en kaliteli malzemeyi hastalarında kullanmaya dikkat etmelidir.
\end{abstract}

Anahtar sözcükler: ortopedi ve travmatoloji; malzeme; yasal prosedürler; maliyet-yarar; kalite
Medical implants take an important place in orthopaedic surgeries. An orthopaedic physician has to follow latest technology while choosing the most suitable implant for his/her patient. However, in this preference, the legal procedures in our country, the limitations of the insurance institutions, and the patient-related factors must also be taken into account. In this study, it is aimed to emphasize the legal procedures that should be taken into consideration with Health Application Communiqué (SUT) when using the most appropriate medical implants by an orthopedic physician specifically working in a public hospital. One of the most important factors determining the use of medical implants in our country is the Social Security Institution's (SGK) reimbursement restrictions and pricing policies. The SUT, which was first published in 2010 and then updated according to the needs, sets the limits of the medical devices that orthopedists working in public hospitals can use for reimbursement. The use of certain products in the SUT lists is subject to special conditions. For this reason, the physician should always follow the current SUT when selecting medical implants. Inadequate pricing in spite of the increasing firm expenses (raw material, exchange rate, cost, employment, insurance etc.), and giving one price to the same SUT code without any distinction of quality, causes especially the firms that occupy an important place in the world market, which are trying to offer quality products, to withdraw from the country market. This leads to a decrease in the quality of the implants used, a decrease in the success of the operations performed, and an increase in the revision rates day by day. In this regard, especially domestic productions should be supported, their quality should be improved, research and development units should be developed. It is important that all implants or devices are passed through inspection and quality control systems. The physician has to take into account the conditions of the country, the expectations and life standards of the patient, paying attention to the legal procedures (SUT provisions) and the use of the highest quality and the most cost-effective one while choosing the appropriate implant.

Key words: implants in orthopaedics and traumatology; legal procedures; cost-effectiveness; quality

- Illetişim adresi: Op. Dr. Mustafa Caner Okkaoğlu, Sanatoryum Cad. Pınarbaşı Mah. Ardahan Sok. No:25 Pınarbaşı, Keçiören, Ankara Tel: 0507 - 9588285 e-posta: canerokkaoglu@yahoo.com

- Geliș tarihi: 9 Ekim 2019 Kabul tarihi: 19 Aralık 2019 
elişen teknoloji ve tıbbi malzemeler sayesinde hastaların tedavilerindeki sonuçlar olumlu yönde etkilenmektedir, fakat bu durum özellikle Ortopedi ve Travmatoloji alanındaki cerrahları tıbbi malzemelere ve cihazlara daha bağımlı hale getirmektedir. Bir hekim hastası için en uygun tıbbi tedaviyi uygularken; hastanın yaşına, aktivite düzeyine, sosyoekonomik yaşam standartlarına göre kaliteli ve maliyet-yarar oranı en uygun malzemeyi seçmeli, bulunduğu ülkenin şartlarını, yasal prosedürleri de göz önünde bulundurmalıdır. Ortopedi ve Travmatolojide doğru malzeme yönetimi için dikkate alınması gereken durumları üç başlık altında toplayabiliriz.

1. Ortopedi ve Travmatoloji alanında malzeme seçimi ve etkileyen faktörler

2. Ülkemizde malzeme kullanımı için yasal prosedürler

3. Ülkemizde malzeme kullanımında yapılan hatalar, Sağlık Uygulama Tebliği'ndeki (SUT) eksiklikler ve kaliteyi artırmak için çözüm yolları

Bu çalışmada amaç; yasal prosedürlere uygun şekilde bir tıbbi malzemenin kullanımı için dikkat edilmesi gereken kuralları sunmaktır.

\section{ORTOPEDI VE TRAVMATOLOJI ALANINDA MALZEME SEÇIMI VE ETKILEYEN FAKTÖRLER}

Ortopedik cerrahide kullanılacak ideal bir implantın; yumuşak dokular tarafindan fiziksel olarak etkilenmemesi, yabancı cisim reaksiyonuna, inflamasyona, alerji ve aşırı duyarlıığa neden olmaması, kimyasal olarak inert olması, karsinojenik olmaması, yapısını ve devamlılığını vücut içinde de koruyabilmesi, istenilen şekli alabilmesi, sterilize edilebilmesi ve yeterli mekanik özelliklere sahip olması gerekmektedir. ${ }^{[1,2]}$ Ortopedi ve Travmatoloji alanında implant üretimi yapılırken, cinsi ne olursa olsun malzeme bu özelliklere sahip olmalıdır. Bu özelliklere sahip metaller, seramikler, polimerler ve kompozitlerin üretimi, araştırma geliştirme aşamaları yüksek maliyetler altında yapılmaktadır.

Amerika Birleşik Devletleri'nde (ABD) yılda yapılan sağlık harcamaları 3,3 trilyon doları geçmiş durumdadır, bunun ise 2025'e kadar her yıl ortalama \%5,6 kadar artması beklenmektedir. ${ }^{[3,4]}$ Bu harcamalar içinde ortopedik cerrahi, sigorta sistemleri için büyük mali yüklere neden olmaktadır. Genel sağlık hizmetleri kapsamında ABD'de en fazla harcama ortopedik cerrahi prosedürlere gitmektedir. Bu cerrahilerde de en büyük maliyet kalemi kullanılan malzemelerdir. Son yıllarda yapılan bir çalışmanın bulgularına göre, total kalça ve diz artroplastisi ameliyatlarında kullanılan implantın maliyeti tüm cerrahi prosedürün fiyatının ortalama \%43-50'sine ulaşmaktadır; bazı cerrahilerde bu oran \%87'ye kadar çıkabilmektedir. ${ }^{[5]}$ Aslında Amerikan Ortopedi Cerrahları Derneği (American Academy of Orthopaedic Surgeons -AAOS) dâhil birçok otorite, malzeme yönetiminde cerrahların maliyetleri göz önüne alması gerektiğini, karar aşamasında bunun da etkili olması gerektiğini önerse de pratikte, cerrahların çoğu kullanılan malzemelerin fiyatlarını dahi bilmemektedirler. ${ }^{[6-8]}$

Westerlain ve ark., yaptıkları bir çalışmada; 223 ortopedi uzmanının üst ekstremite kırıklarında kullanacakları malzeme seçiminde dikkat ettikleri faktörleri araştırmıştır. Uzmanlara malzeme seçimini etkileyebilecek faktörlerin olduğu bir anket verilmiş ve en çok dikkat ettikleri üç faktör sorulmuştur (Tablo 1). Anket sonuçlarına göre, malzeme seçiminde en etkili üç faktör sırasıyla; 1) o implanta aşinalık ve kullanım alışkanlığı, 2) kanıta dayalı kılavuzlara ve literatüre göre seçim, 3) en güvenli kırık iyileşmesi sağlayan malzemeler olarak

Tablo 1. Westerlain ve ark. çalışmasındaki ankette yer alan malzeme seçimini etkileyen faktörler ${ }^{[9]}$

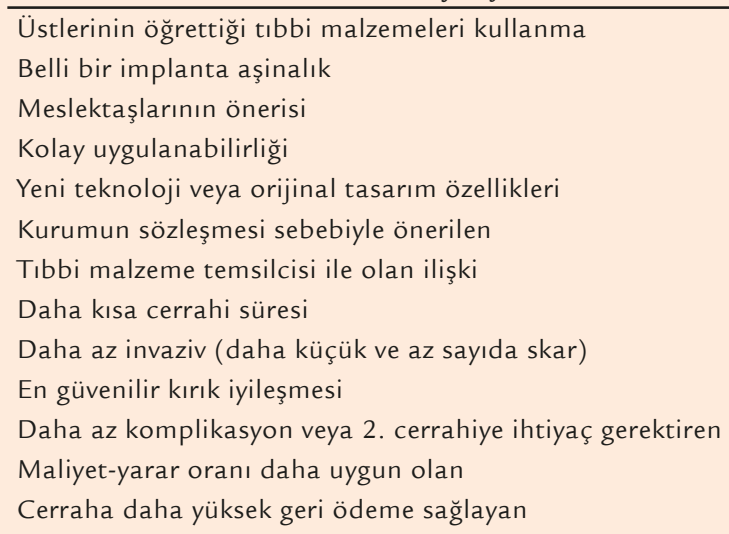




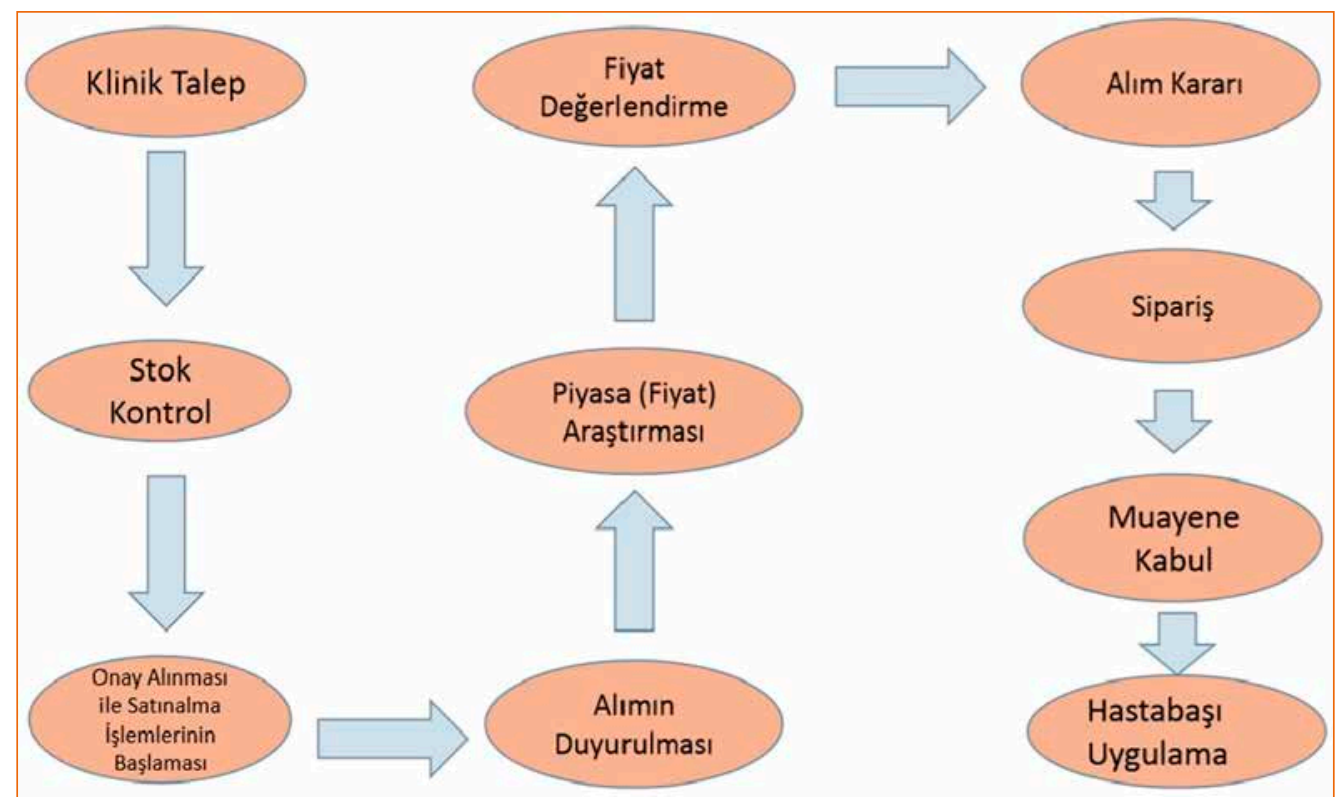

Şekil 1. Kamu ihale Kanunu'nun 22/F maddesine göre alımların kısa özeti.

bulunmuştur. Yine bu çalışmada, malzeme seçiminde implant fiyatları önemli bir faktördür diyenlerin oranının sadece \%11 olduğu bildirilmiştir. ${ }^{[9]}$ Aslında, bu çaIışmada sunulan malzeme seçiminde ortopedi uzmanlarının tercih nedenleri Türkiye'de de kısmen geçerlidir diyebiliriz. Fakat, ülkemizde özellikle kamu hastanelerinde çalışan hekimlerin tercih nedenlerini etkileyen en önemli faktörlerden biri de Sosyal Güvenlik Kurumu (SGK) geri ödeme hükümleri ve fiyatlandırmalarıdır.

\section{ÜLKEMIZDE MALZEME KULLANIMI IÇiN YASAL PROSEDÜRLER}

Ülkemizde Ortopedi ve Travmatoloji ile Beyin Cerrahisi gibi bölümlerin ameliyatlarında kullanılan malzemelerin temini, bu dallardaki cerrahi malzemelerin çeşitliliği ve malzeme kullanımlarının artmasına bağlı olarak, sigorta kurumlarına artan bir maliyet yüklenmesine neden olmuştur. SGK da, malzeme temini ve geri ödeme için bugüne kadar farklı yöntemler benimsemiştir. Sağlık Uygulama Tebliği (SUT); 5502 sayılı SGK Kanunu, 5510 sayılı Kanun ve "Genel Sağlık Sigortası İşlemleri Yönetmeliği” hükümleri çerçevesinde düzenlenmiş ve Ortopedi alanında 2010 yılında ilk olarak yayımlanmıştır. SUT ile, yatan hastalarda kullanılan tıbbi malzemeler için hastanelere bunları temin etme sorumluluğu verilmiştir. ${ }^{[10]}$ Fakat, sorumluluğu kullanırken bu teminlerin Kamu ihale Kanunu uyarınca yapılması istenmiştir. Teminlerin mümkün olduğunca açık ihale sistemine göre yapılması istenmişse de, bunlar ülkemizin büyük kısmında Kamu ihale Kanunu'nun
22. madde $\mathrm{F}$ bendi uygulanarak yapılmaktadır. Bu maddeye göre; "özelliğinden ve belli süre içinde kullanılma zorunluluğundan dolayı stoklanması ekonomik olmayan veya acil durumlarda kullanılacak olan ilaç, serum, anti-serum, kan ve kan ürünleri ile ortez, protez gibi uygulama esnasında hastaya göre belirlenebilen ve hastaya özgü tıbbi sarf malzemeleri, test ve tetkik sarf malzemeleri alımları, ilan yapılmaksızın ve teminat alınmaksızın doğrudan temin ile alınabilir" uyarısı gereğince işlem yapılmaktadır.

Mevcut durumda Ortopedi ve Travmatoloji alanındaki malzemelerin temin şekilleri hastaneden hastaneye değişebilmektedir. Bazı hastane veya il sağlık müdürlükleri kendi açık ihale sistemleri, ya da "belirli süreli 22/F sözleşmesi” ile malzeme alımlarını yapmaktadır ve burada çalışan cerrahlar da, istisnai durumlar olmadığı takdirde, bu malzemeleri kullanmaktadırlar. Fakat ülkemiz genelinde sıklıkla kullanılan yöntem, yukarıda da bahsedildiği gibi, teminlerin Kamu ihale Kanunu'nun 22/F maddesi kullanılarak hasta başı yapılmasıdır. Bu da, hasta bazlı olarak gereken malzemenin SUT fiyatlandırmasına uygun şekilde doğrudan firmalardan ya da bayilerden pazarlık yöntemi ile temin edilmesidir. Malzemelerin 22/F üzerinden temin süreci Şekil 1'de kısaca gösterilmiştir.

Temin edilen tıbbi malzemelerin ödemeleri, SGK tarafından her malzeme grubuna özel SUT kodlarına göre fiyatlandırmalar üzerindendir. Hastane yönetimleri belli bir ürün kodunda olan malzeme için SUT fiyatı üzerinden en fazla indirimi yapan firmadan 
ürünü temin etmeye çalışır. Illgili koda uyan malzemelerin SGK'dan geri ödemelerinin alınması için SUT'ta belirlenmiş olan temel kurallar şu şekilde özetlenebilir:

1. Kullanılan malzemelerin Türkiye illaç ve Tıbbi Cihaz (TiTCK) Ulusal Bilgi Bankasına (TiTUBB)/Ürün Takip Sistemi (ÜTS)'ne kayıtlı olması gereklidir.

2. Tıbbi malzeme alan tanımları (SUT kodları), SUT eki EK-3 listelerinde yer almaktadır. Tıbbi malzemeler bu SUT kodları ile Kuruma fatura edilebilir.

3. Tıbbi malzeme imal veya ithal eden firmalar tıbbi malzemelerini; Kurumca duyurulan yöntemlerle ve/veya Kurumca yayımlanan Tıbbi Malzeme Başvuru Kılavuzu kapsamında SUT eki EK-3 listelerindeki tıbbi malzeme alan tanımlarına, küresel ürün numarası (barkod) bazında tanımlar. SUT kodları bazında MEDULA (MEDikal+ULAk) sisteminde işlem tarihinde tanımlı olmayan tıbbi malzemelerin bedelleri Kurumca karşılanmamaktadır.

4. Barkod - SUT kodu eşleştirmelerinin hatalı olduğunun herhangi bir şekilde tespit edilmesi veya tıbbi malzemelerin Kurumca belirlenen kural ve/ veya kriterlere uygunsuz bir şekilde fatura edilmesi halinde, söz konusu tıbbi malzeme bedelleri ödenmez, ödenmiş ise ilgililerden yersiz ödeme kapsamında tahsil edilir.

5. Ödeme kural ve/veya kriterlerinde sağlık hizmet sunucusu kısıtı bulunan tıbbi malzemelerin faturalandırıldığı SUT eki işlem bedellerinin ödemesinde de aynı kısıt aranır. Tıbbi malzemelerdeki sağlık hizmet sunucusu kısıtına uymayan işlemlerin bedelleri ödenmez.

6. Adetleri günlük/haftalık/aylık vb. olarak reçetelendirilebilen tıbbi malzemelerin, SUT'ta belirtilen miktarlardan fazla reçetesi durumunda, SUT'ta belirtilen kullanım adetleri doğrultusunda bedelleri Kurumca karşılanır.

Ortopedi ve Travmatoloji alanındaki cerrahi ile ilgili SUT tıbbi malzeme listelerinin hangi ekte olduğu Tablo 2'de verilmiştir. ${ }^{[10]}$

Bu malzeme istemlerinde SGK tarafindan geri ödeme alınabilmesi için SUT güncellemelerini, özellikle kamu hastanelerinde çalışan Ortopedi ve Travmatoloji uzmanlarının takip etmeleri gerekmektedir. Yapılan güncellemelerde bazı malzemelerin geri ödeme kapsamında olması için ek şartlar getirilebilmekte, belli malzemelerin sadece 3. basamak hastanelerde kullanılmasına izin verilebilmekte, ek sağlık kurulu raporları istenebilmektedir. Özellikle kamu hastanesinde çalışan bir Ortopedi ve Travmatoloji hekiminin, SUT hükümleri doğrultusunda hangi malzemeyi ne miktarda kullanabildiğini bilmesi; ameliyat sonrası üç imzalı malzeme kullanım raporlarını imzalarken, fatura içeriğinin SUT hükümlerine uygun, SUT kodlarıla eşleştirmelerinin doğru olduğundan emin olması gerekir.

SUT'taki kısıtlamalara örnek greftler üzerinden verilebilir (Tablo 3). ${ }^{[10]}$ Bu hükümlere aykırı kullanımlarda SGK tarafindan greftlerin geri ödemesi yapılmamaktadır. Eşleştirme yapılan ürünün doğruluğundan emin olunmalıdır. Gerek endikasyon kurallarına uyma gerekse yanlış eşleştirme nedeniyle hatalar en fazla greft kullanımlarında olmaktadır. Viskosuplementler 2008 yılından itibaren SGK tarafından geri ödeme kapsamından çıkarıldığı halde, yanlış eşleştirme nedeniyle fatura edilebilmektedir. Kollajen adı altında bazı ürünler bu kısma eşleştirilerek greft endikasyonlarına aykırı bir şekilde kullanılabilmektedir.

SUT hükümlerine göre, bazı tıbbi malzemeler sadece eğitim verme yetkisi olan 3 . basamak resmi sağlık kurumlarında kullanılması halinde geri ödeme kapsamına alınmıştır (Tablo 4). ${ }^{[10]}$ Ayrıca, bu malzemelerin kullanımı için SUT'ta özel şartlar da yer almaktadır. $\mathrm{Bu}$ malzemelerin diğer sağlık kurumlarında kullanılması durumunda, hem hekim hem de tedarikçi firma zor durumda kalacak ve ürün geri ödemesi olmayacaktır.

Bunların dışında belirli malzemelerin kullanımlarında, sadece Sağlık Bakanlığı tarafından oluşturulan "Ortopedi Bilimsel Danışma Kurulu" adlı komisyon tarafından onay alınması şartı ile bunların bedelleri karşılanır (Tablo 5). ${ }^{[10]}$ Bu malzemeler kullanılmadan önce, hasta bilgilerinin yer aldığı bir dosya hazırlanarak bu komisyona başvurulur ve sonucuna göre malzeme kullanımına izin verilir.

Sonuç olarak; burada verilen örnekler SUT'taki özel şartların bir kısmıdır. Bu nedenle, bir kamu hastanesinde çalışan Ortopedi ve Travmatoloji uzmanı, hastanenin satın alma birimi ve tedarikçi firma; bunların her üçünün de yasal prosedürlere hakim olması, SUT hükümlerini iyi bilmesi gerekir. Bu, ileride oluşabilecek ihtilaflı durumların oluşmasına, soruşturmalara belki de alınabilecek hukuki cezalara engel olacaktır. SGK; SUT hükümleriyle yanlış kullanımları, fahiş fiyatları engellemeye çalışmakta, hasta için en uygun malzemeyi en uygun fiyata temin etmeye çalışmaktadır.

\section{ÜLKEMIZDE MALZEME KULLANIMINDA YAPILAN HATALAR, SUT'TAKI EKSIKLLIKLER VE KALITEYI ARTIRMAK IÇIN ÇÖZÜM YOLLARI}

SUT'taki Tablo 6'da verilen uygulama hataları nedeniyle, ülkemizde düşük kalite tıbbi malzemelerin kullanımı artmaktadır. SUT; her bir tıbbi malzemenin bir SUT koduna eşleştirilmesini istemekte ve her SUT 
Tablo 2. Ortopedik cerrahi ile ilgili SUT Listeleri

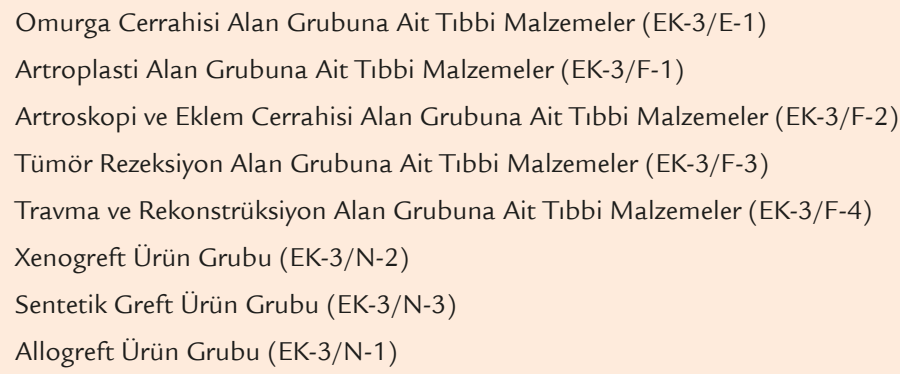

Tablo 3. SUT'a göre greftler ile ilgili kısıtlamalar

1. Sentetik greftler ve xenogreftler tıbbi cihaz yönetmeliği kapsamında oldukları için TiTUBB/ÜTS'ye kayıtlı olması gerekir.

2. Epifiz hattı açık olan patolojik olmayan primer kırıklarda greft bedelleri karşılanmaz.

3. Sentetik greft, allogreft ve xenogreftlerin birbirleriyle kombine edilerek kullanımları kurumca karşılanmaz.

4. Sentetik greftler olgu başına en fazla $30 \mathrm{cc}$, allogreft ve xenogreftler ise en fazla 60 cc kullanılabilir.

5. Spinal cerrahide greft kullanılması için en az üç seviye füzyon olması gerekir.

6. Allogreft ve xenogreftler büyük kemik kistlerinde aksiyel ve koronal kesitlerine ait raporlarla belgelendirilmek kaydıyla 120 cc'ye kadar kullanılabilir.

7. Tendon greftleri eğitim verme yetkisi olan üçüncü basamak hastanelerde kullanılabilir.

8. Revizyon rekonstrüksiyon ameliyatlarında en fazla bir, çoklu bağ yaralanmalarında en fazla iki adet allogreft tendon kullanılabilir; primer olgularda kullanılamaz.

Tablo 4. Sadece eğitim verme yetkisi olan üçüncü basamak resmi sağlık kurumlarında bedeli karşılanacak olan malzemeler
1. Taze donmuş (fresh frozen) allogreft
10. Bilgisayar destekli intramedüller uygulamalar
2. Tümör rezeksiyon protezi
11. Sentetik menisküs implantları
3. Menteşeli diz protezi
12. Hücresiz kıkırdak matriksleri
4. Teleskopik çiviler
13. Hücresiz menisküs implantları
5. Proksimal femur başlı/başsız ile femoral baş allogreftler
14. Absorbe olabilir omuz balon spacer
6. Tendon allogreftleri
15. Rijit olabilen intramedüller elastik çiviler
7. Kortikal şaft allogreftler
16. Uzatma yapabilen intramedüller çiviler -motorlu/manyetik
8. Sinus tarsi vidası
17. Yüzey yenileme implantları

9. Bilgisayar destekli / Uzaysal eksternal fiksatörler

Tablo 5. Ortopedi Bilimsel Danışma Kurulu tarafında onay alınması gereken malzemeler
a) Kişiye özel tasarımlı üretilen protezler
b) Tümör dışı endikasyonlarda kullanılan tümör rezeksiyon protezleri, interkalar segmentler ve artrodez aparatları
c) Manyetik/mekanik olarak uzatılabilen tümör rezeksiyon protezleri
d) Kıkırdak hücre kültürleri

Tablo 6. Ülkemizde düşük kalite tıbbi malzemelerin kullanımlarının artma nedenleri
1. SGK'nın her SUT koduna kalite ayrımı yapmaksızın sabit - tek fiyat politikası
2. CE ve ISO belgelerinin yeterli olduğunun düşünülmesi, ancak bunların kalite göstergesi olmaması
3. İhale sisteminin yanlış uygulanması; satın alma birimlerinin yeterli bilgiye sahip olmaması
4. Eşleştirme hataları
5. SGK'nın ve TiTCK'nın denetim/gözetim görevini yerine getirememesi 
koduna da kalite ayrımı yapmaksızın tek bir fiyat vermektedir. SGK'nın SUT'u bu şekilde yayımlamasındaki temel amaç; benzer tıbbi malzemeleri aynı kodlar etrafinda toplayarak, faturalandırmayı daha basite indirgemek ve kullanıcı hekimleri SUT fiyatını aşmayacak şekilde tıbbi malzeme kullanımlarında özgür bırakmak gibi görünmektedir. Hastane Satınalma Birimleri bu tıbbi malzemeleri alırken, firma ile ister açık, isterse çerçeve, isterse de doğrudan alım şeklinde olsun pazarlık ederek SUT fiyatı üzerinden iskonto yaptırmaya çalışmaktadır. Ancak, Satınalma Birimlerinde çalışan görevlilerin tıbbi malzemeleri bilmemesi, firmaların kendi ürünlerini yüksek kalitelilerle eş görmesi, bu ürünlerin tamamının benzer iskonto oranlarıyla temin edilmesine neden olmaktadır. Bundan da en büyük zararı, tedavisinde düşük kalite malzeme kullanılan hasta görmektedir. Ne yazık ki, bazı hekimlerimiz de bu düşük kalite tıbbi malzemeleri hastalarına kullanmaktadırlar. Oysa ki, tüm dünya tarafından kabul görmüş, uzun dönem sonuçları olan, biyomekanik sonuçları belli yüksek kaliteli ürünlerle, bu düşük kalite malzemelerin fiyatı SGK tarafindan eşit olarak ödenmektedir. Malzeme fiyatı bir hastanede düşük verildiğinde, bu düşük fiyat tüm ülke genelinde MEDULA Sistemi'nde görüldüğü için, bu ürünleri hastane bazında dahi olsa pazarlayan firmalar buna uyarak fiyat düşürmek istememektedir.

Ülkemizde kullanılan tıbbi malzemelerin kalitesini inceleyen kalite kontrol laboratuvarları işlevsel değildir. Tıbbi malzemelerin kalitesinin, bu malzeme örnekleri çeşitli ölçü ve test aletlerinden geçirilerek yapılan biyomekanik inceleme sonucu, bu laboratuvarlarda belirlenmesi gerekir. Normalde, yüksek kaliteli bir tıbbi malzemenin üretiminde; hammaddeden sterilizasyon koşullarına, etiketten taşıma koşullarına, klinik araştırma ve biyomekanik çalışmalardan toksik duyarlılığa kadar tüm standartlara dikkat edilir. Ancak, atölye tarzı yerlerde üretilen ve asgari özellikleri sağlayarak TSE, CE belgesi alan düşük kalite tıbbi malzemelerin üretim maliyetini artırıcı işlemlerden kaçınılmakta ama SUT'ta kalitesi yüksek ürünlerle eş tutulmakta ve aynı fiyatı almaktadır. Sonuç olarak; kısa dönemde gevşeyerek revizyona giden, ameliyat esnasında ya da tedavi süresince kırılan, uygulama setleri kalitesiz implantlarla yapılan ameliyatların sayıları sürekli artış göstermektedir. Komplikasyonlar, iyileşme sürecini uzatarak uzun hastane kalım süresi, enfeksiyonlar, fizyoterapi ve yeniden implant kullanımı gibi nedenlerle tedavi maliyetlerini ciddi oranda artırmaktadır.

SGK'nın yanlış SUT fiyat politikası sonucunda, öncü firmaların tasarımlarını taklit ederek piyasaya giren firmalar, ürününü kopyaladıkları firmalarla eşit fiyat aldıkları için pazardan ciddi pay almaktadır. Bunlar, yeni teknolojileri geliştirmek için ARGE (Araştırma ve
Geliştirme)'ye ve eğitime kaynak ayıran firmalar karşısında, düşük maliyetle ve düşük kalitede ürettikleri ürünlerle avantajlı duruma geçmektedir.

Yeni teknolojik ürünler, SUT'un bu eşit fiyat politikası sonrasında ya pazardan çekilmiş ya da bunları pazara sürmekten vazgeçilmiştir. Artık, kaliteli kabul edilen markalar dahi, yeni nesil değil önceki nesil ürünleri piyasaya arz etmektedir. Son yıllarda yeni bir ürün piyasaya sürülmemiştir. Yüksek kalite ürünlerin pazar paylarının da giderek azaldığı dikkat çekmektedir.

\section{ÇÖZÜM ÖNERILERi}

1. Ürünlerin mutlaka bir kalite sınıflandırmasına tabi tutulması ve fiyatlandırmanın SGK tarafindan kaliteye göre yapılması. Yüksek kalite sınıfında olabilmek için;

a. Ürünün patentli tasarım olması,

b. ABD, Batı Avrupa ve Japonya gibi standartları yüksek ülkelerde satışının yapılıyor olması,

c. SCl/Pubmed'deki bilimsel dergilerde yayımlanmış kısa-orta-uzun dönem sonuçları içeren çalışmalarının olması,

d. Sadece TSE, CE belgesinin değil, beraberinde biyomekanik çalışmaları da içeren bir dosyasının, kurulacak olan bilimsel komisyon tarafindan değerlendirilmesi,

2. Üniversitelerin Tıp, Biyomekanik, Makine Mühendisliği, Metalurji gibi bölümleri ile Tıbbi İlaç ve Cihaz Kurumu ve sektör Sivil Toplum Kuruluşlarının bir araya gelerek milli kalite standardımızı oluşturması ve bu standarda göre Piyasa Denetim ve Gözetimi sağlanarak kaliteli tıbbi malzeme kullanımının sağlanması,

3. Düşük kalite olduğu bilinen, ancak hekimlerce tercih edilen ve SUT'ta yüksek kalite malzemelerle fiyat anlamında eş kabul edilen düşük kalite ürünlerin tercih sebeplerinin ortaya konulması gerekmektedir.

Bu sorunların çözümü yolunda girişimlere başlanılmadığı takdirde; komplikasyonların çok artması nedeniyle, yakın zamanda maliyetlerimizin çok daha arttığını görmek zorunda kalacağımızı söylemek doğru olacaktır.

\section{SONUÇ}

Sonuç olarak Ortopedi ve Travmatolojide malzeme seçimi yaparken öncelikle literatüre ve kanıta dayalı en kaliteli malzemeyi kullanmak ilk hedef olmalıdır. Fakat bu hedef doğrultusunda seçim yaparken, hastanın beklentilerini ve yaşam standartlarını, 
maliyet-yarar analizini, yasal prosedürleri, etik gereklilikleri de göz önüne almamız gerekmektedir. Bununla ilgili, yasa koyucuların da gerekli önlemleri alarak kaliteyi artırmaya yönelik çaba içinde olmaları önem arz etmektedir.

\section{KAYNAKLAR}

1. Park BJ, Bronzino JD, editors. Biomaterials: Principles and Applications. New York: CRC Press; 2003. Erişim: https:// archive.org/details/0849314917.CRC.Biomaterials. Principles. and.Applications.Aug. 2002

2. Altıntaş M. Klinik gelişim. İstanbul Tabip Odası 1994;12:3408-12. http://www.klinikgelisim.org.tr/eskisayi/ arsiv.html

3. CenterforMedicare \&Medicaid Services(CMS). National Health Care Spending In 2016. Highlights 2016. pp.10-18. Erişim: https://www.cms.gov/Research-Statistics-Data-and-Systems/ Statistics-Trends-and-Reports/NationalHealthExpendData/ Downloads/NHE-Presentation-Slides.pdf

4. Center for Medicare \& Medicaid Services (CMS). 2016-2025 Projections of National Health Expenditures Data Released. Erişim: https://www.cms.gov/newsroom/press-releases/20162025-projections-national-health-expenditures-data-released
5. Robinson JC, Pozen A, Tseng S, Bozic KJ. Variability in costs associated with total hip and knee replacement implants. J Bone Joint Surg Am 2012;94(18):1693-8. Crossref

6. American Academy of Orthopaedic Surgeons. Value Driven Use of Orthopaedic Implants. Erişim: http://www.aaos.org/ uploadedFiles/PreProduction/About/Opinion_Statements/ position/1104\%20Value\%20 Driven\%20Use\%20 of\%20 Orthopaedic\%20Implants(1).pdf

7. Okike K, O'Toole RV, Pollak AN, Bishop JA, McAndrew CM, Mehta S, Cross WW, Garrigues GE, Harris MB, Lebrun CT. Survey finds few orthopedic surgeons know the costs of the devices they implant. Health Aff (Millwood) 2014;33(1):1039. Crossref

8. Streit JJ, Youssef A, Coale RM. Carpenter JE, Marcus RE. Orthopaedic surgeons frequently underestimate the cost of orthopaedic implants. Clin Orthop Relat Res 2013;471(6):1744-9. Crossref

9. Wasterlain AS, Melamed E, Bello R, Karia R, Capo JT; Science of Variation Group. The effect of price on surgeons' choice of implants: a randomized controlled survey. J Hand Surg Am 2017;42(8):593-601. Crossref

10. Sağlık Uygulama Tebliği (SUT). Erişim: http://mww.sgk.gov.tr/ wps/wcm/connect/d9874908-6a4e-4756-96dd-7268f09e0793/ duyuru_20190913_11.pdf?MOD=AJPERES\&CONVERT_

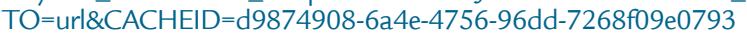

